\title{
Using Unmanned Aerial Vehicles (UAV) for forest damage monitoring in south-western Europe
}

L. A. Pérez-Rodríguez, C. Quintano, P. García-Llamas, V. Fernández-García, A. Taboada, et al.

L. A. Pérez-Rodríguez, C. Quintano, P. García-Llamas, V. Fernández-García, A. Taboada, J. M. Fernández-Guisuraga, E. Marcos, S. Suárez-Seoane, L. Calvo, A. Fernández-Manso, "Using Unmanned Aerial Vehicles (UAV) for forest damage monitoring in south-western Europe," Proc. SPIE 11130, Imaging Spectrometry XXIII: Applications, Sensors, and Processing, 111300K (6 September 2019); doi: 10.1117/12.2531265

Event: SPIE Optical Engineering + Applications, 2019, San Diego, California, United States 


\title{
Using Unmanned Aerial Vehicles (UAV) for forest damage monitoring in south-western Europe
}

\author{
Pérez-Rodríguez L.A.' ${ }^{1,}$ Quintano, C., ${ }^{2,3}$, García-Llamas, P. ${ }^{4,5}$, Fernández-García, V.,5, \\ Taboada, A. ${ }^{4,5}$, Fernández-Guisuraga, J.M. ${ }^{4,5}$, Marcos, E. ${ }^{4,5}$, Suárez-Seoane, S. ${ }^{4,5}$, Calvo, L. ${ }^{4,5}$ \\ Fernández-Manso, A. ${ }^{1}$
}

${ }^{(1)}$ Agrarian Science and Engineering Dpt., University of León, Av. Astorga s/n, 24400- Ponferrada, Spain

${ }^{(2)}$ Electronic Technology Dpt., Engineering School. University of Valladolid, Paseo del Cuace, 59, 47011-Valladolid, Spain

(3) Sustainable Forest Management Research Institute, Universidad of Valladolid, Spanish National Institute for Agriculture and Food Research and Technology (INIA), Spain

(4) Biodiversity and Environmental Management Dpt., Faculty of Biological and Environmental Sciences, University of León, Campus de Vegazana s/n, 24071-León, Spain

${ }^{(5)}$ Institute of Environmental Research (IMA), University of León, 24071-León, Spain

\begin{abstract}
Prescribed burns are being considered as a management tool for the prevention of forest fires in many countries that have important firefighting problems. Knowledge of fire intensity and eliminated vegetation fuel are of great interest to evaluate their effectiveness. Both parameters are directly related to burn severity, so their evaluation is fundamental to predict the post-fire evolution of burned area. In this study we evaluated two prescribed burnings carried out in North of Spain during October 2017 by using multispectral data from an Unmanned Aerial Vehicle (UAV). In particular, four surface reflectance images were obtained in green $(550 \mathrm{~nm})$, red $(660 \mathrm{~nm})$, red-edge $(735 \mathrm{~nm})$ and near infrared $(790 \mathrm{~nm})$ at very high spatial resolution (GSD $20 \mathrm{~cm}$ ) from which different spectral indexes were computed. Additionally, vegetation and soil burn severity was measured in 153 field plots and an analysis of variance (ANOVA) between each spectral index and burn severity (both in vegetation and soil) was performed. A Fisher's least significant difference test determined that three vegetation burn severity levels and two soil burn severity levels could be statistically distinguished. The identification of such burn severity levels is sufficient and useful to forest managers. We conclude that multispectral data from UAVs may be considered as a valuable indicator of burn severity for prescribed burnings.
\end{abstract}

Keywords: Unmanned Aerial Vehicles, UAVs; Prescribed burning; Parrot SEQUOIA; Burn severity, ANOVA

\section{INTRODUCTION}

Prescribed burning can be defined as the controlled use of fire to reduce vegetation under specific conditions that allow to fix the intensity of fire and the amount of vegetable fuel to be eliminated according to a proposed objective ${ }^{1}$. Knowing the actual intensity of the fire and the eliminated vegetal fuel is of great interest to evaluate the effectiveness of this type of actions ${ }^{2}$. Both parameters are directly related to the severity of the burn, so its evaluation is fundamental to predict the post-fire evolution of the burned area. The levels of severity of the prescribed burnings have a high spatial heterogeneity

Imaging Spectrometry XXIII: Applications, Sensors, and Processing, edited by Emmett J. lentilucci, Proc. of SPIE Vol. 11130, 111300K · C) 2019 SPIE · CCC code: 0277-786X/19/\$18 · doi: 10.1117/12.2531265 
and will depend on the composition of the plant community prior to the fire and the environmental characteristics during the burning. Therefore, the use of ultra-high spatial resolution images would allow studies of the prescribed burns to evaluate their effectiveness and the effectiveness of the post-fire management actions ${ }^{3}$. Unmanned Aerial Vehicles (UAVs) are an aid in the study of forest fires, which generally implies lower economic costs than other remote sensing techniques when studying relatively small areas. Its low flight speed and flight altitude allow images of ultra-high spatial resolution, less than $20 \mathrm{~cm}^{3}$. In addition, UAVs are flexible in terms of attaching different types of sensors (eg, RGB, multispectral or LiDAR), which also allow the operator to schedule the exact flight time to collect data on target areas. Several research projects have used sensors aboard UAVs, in order to estimate the recovery capacity of vegetation after fire from digital surface models ${ }^{4,5}$.

Red-edge bands have proven their suitability for agricultural applications ${ }^{6}$; land use classification ${ }^{7}$; and forest monitoring ${ }^{8}$. In addition several research works ${ }^{9,10,11}$ have shown their usefulness for burn severity discrimination. All of the studies indicated that standard indices based on nearby red and infrared bands improve their behavior in relation to the study of fire damage when red-edge bands are also used.

In this context, our work will focus on analyzing different red-edge spectral indices from UAV multispectral data and identifying which of them allows significant discrimination of three levels of vegetation and soil burn severity after prescribed burnings. The discrimination capacity of these indexes will be compared to the capacity of commonly used spectral indexes.

\section{MATERIAL AND METHODS}

\subsection{Study zone}

The study area is located in "La Sierra de Uría" (Asturias, North-Western Spain) (Figure 1). The area is $1170 \mathrm{~m}$ altitude, $10 \%$ slope, West orientation, quartzite, very organic and stony soil, with a sandy texture. The area is a heathland whose floristic combination is mainly made up of Erica australis subsp. Aragonensis, Erica cinerea, Erica umbellata, Calluna vulgaris and Daboecia cantabrica. Fuel Model 6 of Rothermell (0.5-1.2 m)

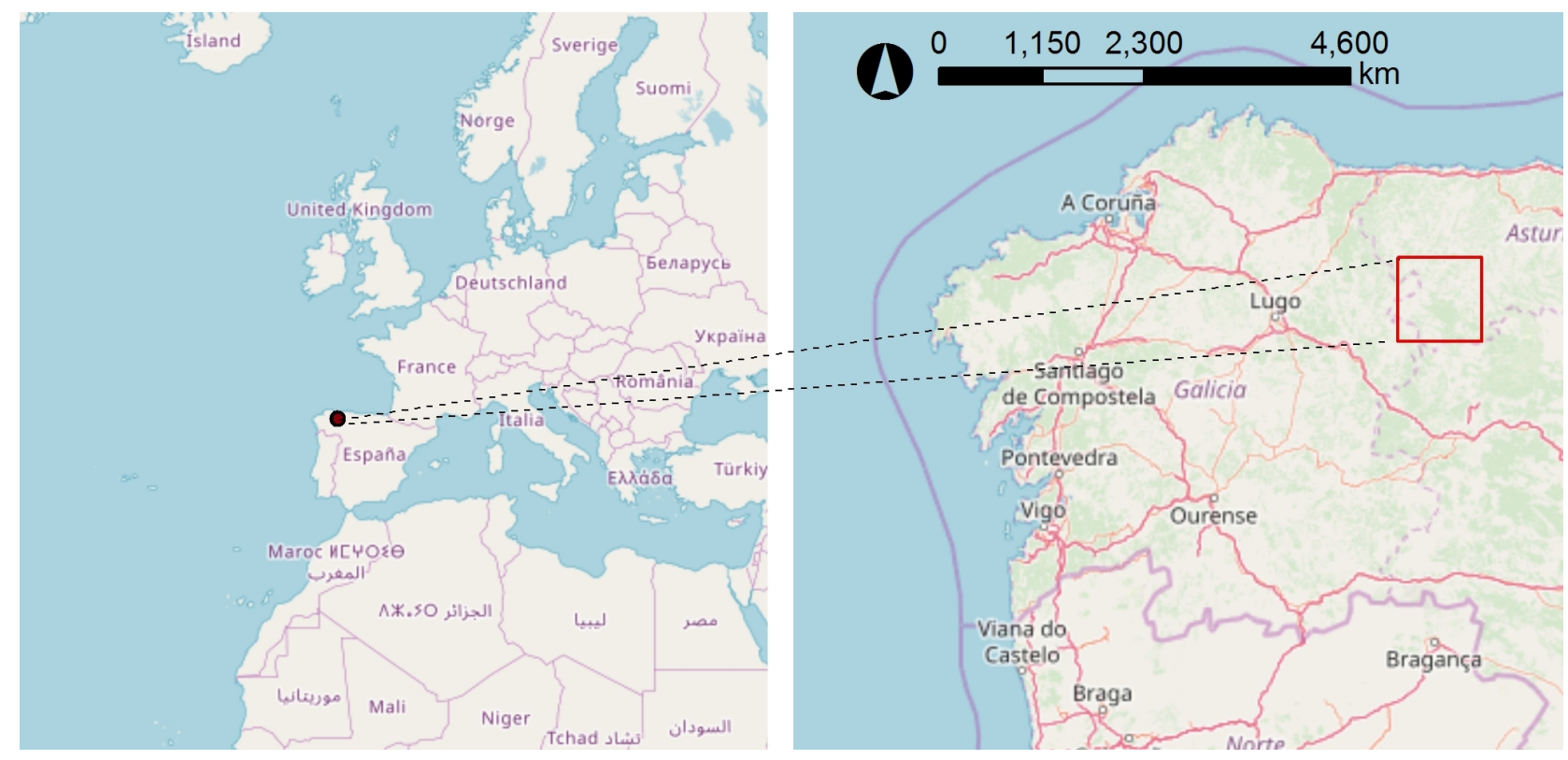

Figure 1. Location of the study area 
Two prescribed burns, both of 7 ha of surface, were performed at the location: $43^{\circ} 6^{\prime} 17^{\prime \prime} \mathrm{N} 6^{\circ} 50^{\prime} 52$ " O (see figure 1). The first of them was carried out on 8 October 2017, and the second one on 15 October 2017. Figure 2 shows some pictures acquired before and after the burnings.
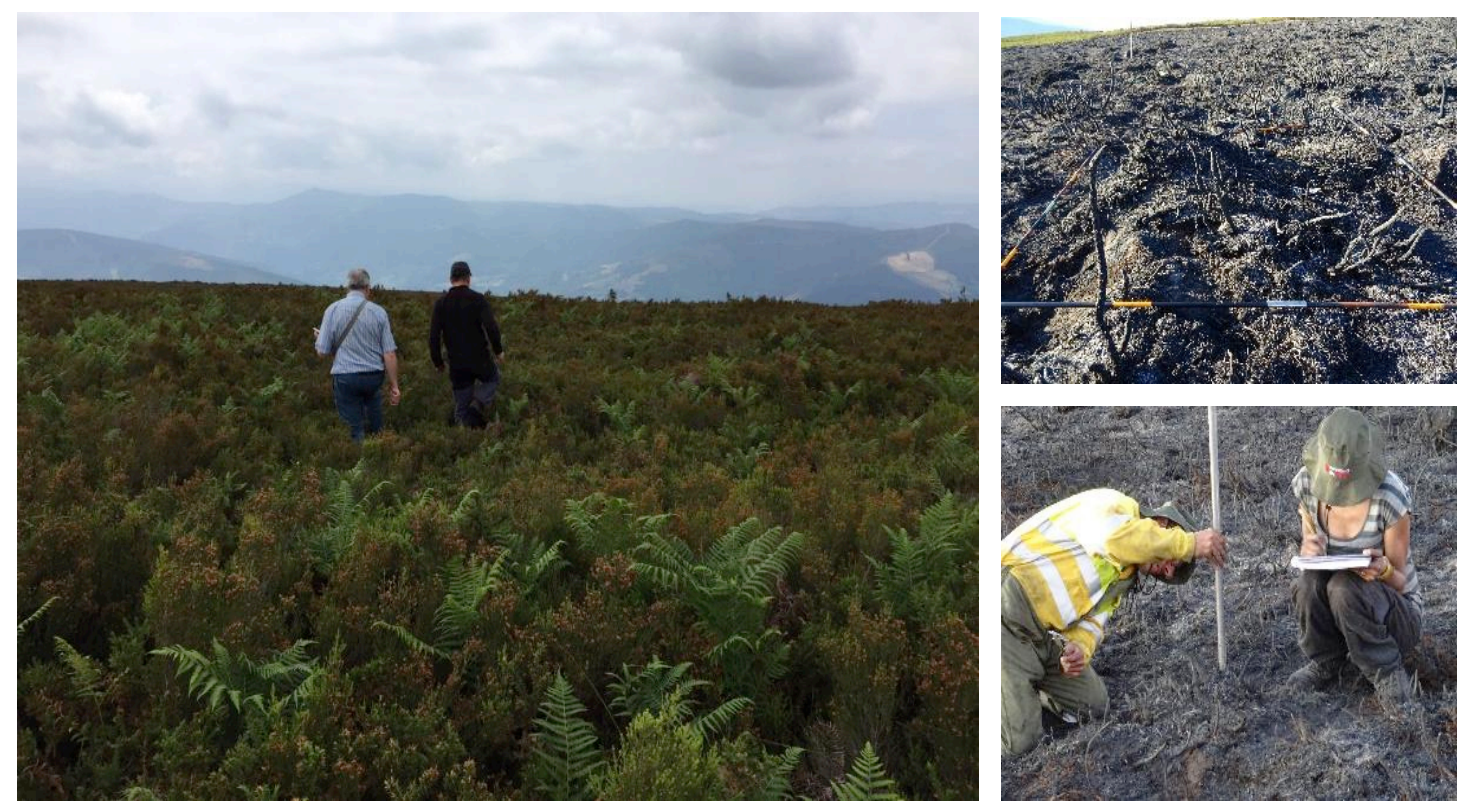

Figure 2. Left: Pre-burning state; right: post-burning state

\subsection{Material}

Our study was based on images taken with a Parrot SEQUOIA multispectral camera aboard of a UAV. This camera has four monochrome 1.2 megapixel sensors that collect global images along four discrete spectral bands: green (central wavelength -CW-: $550 \mathrm{~nm}$, bandwidth -BW-: $40 \mathrm{~nm}$ ), red (CW: $660 \mathrm{~nm}, \mathrm{BW}: 40 \mathrm{~nm})$, red-edge (CW: $735 \mathrm{~nm}$, BW: 10 $\mathrm{nm}$ ) and near infrared (CW: $790 \mathrm{~nm}, \mathrm{BW}: 40 \mathrm{~nm}$ ). The horizontal (HFOV), vertical (VFOV) and diagonal (DFOV) fields of the multispectral camera are $70.6^{\circ}, 52.6^{\circ}$ and $89.6^{\circ}$, respectively, with a focal length of $4 \mathrm{~mm}$. With an average flight altitude of $120 \mathrm{~m}$, a ground sampling distance (GSD) of $14.4 \mathrm{~cm}$ was achieved. The camera is included with an irradiance sensor to record light conditions. Each image capture setting is saved in a text metadata file together with the irradiance sensor data. The flight area covered by the UAV was $0.9151 \mathrm{~km} 2(91.5137 \mathrm{ha})$. The flight was made two weeks after the prescribed burnings (7 November 2017).

Additionally, we measured soil and vegetation burn severity in 153 plots of $1 \mathrm{x} 1 \mathrm{~m}$ adapting the methodology proposed by Key and Benson (2006) ${ }^{12}$ by including the measurement of the apical diameter of the burned vegetation.

\subsection{Methods}

During the pre-processing stage the data acquired by the camera was converted to absolute reflectance values. As an output, four images of surface reflectance were obtained with a GSD of $20 \mathrm{~cm}$ (see figure 3).

From the Parrot SEQUOIA sensor bands in surface reflectance a set of spectral indices with potentiality to identify burned areas and level of vegetation affectation was calculated. The work focused mainly on those indexes that use the "red-edge" bands. The selection of the indexes was based on previous studies ${ }^{6,10,13,14}$. In total, 6 spectral indices were analyzed: Normalized Difference Vegetation Index (NDVI) ${ }^{15}$, used as a reference; Difference Vegetation Index (DVI) ${ }^{15}$, Normalized Difference Vegetation Index red-edge (NDVIre) ${ }^{16}$, Plant Senescence Reflectance Index (PSRI) ${ }^{17}$, Simple Ratio red-edge (SRre) $)^{18}$, and Modified Simple Ratio red-edge $\left(\right.$ MSRre) ${ }^{19}$ (see Table 1). 


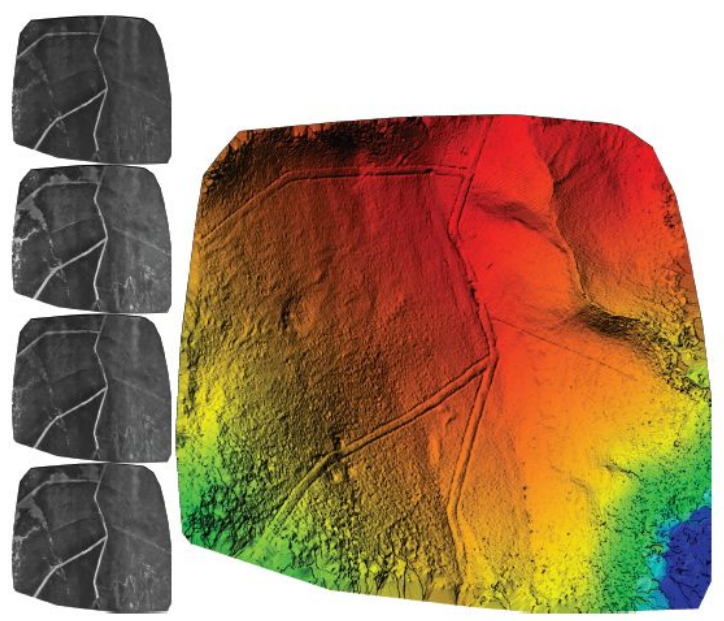

Figure 3. Images of reflectance (left): green, red, red-edge and near-infrared bands from up to down; and Digital Model of Elevations of the study area (right)

Table 1. Spectral indices

\begin{tabular}{|c|c|c|c|}
\hline Acronym & Spectral index & Equation & Reference \\
\hline NDVI & Normalized Difference Vegetation Index & $\frac{N I R-R}{N I R+R}$ & Tucker $(1979)^{15}$ \\
\hline DVI & Difference Vegetation Index & $N I R-R$ & Tucker $(1979)^{15}$ \\
\hline NDVIre & $\begin{array}{l}\text { Normalized Difference Vegetation Index } \\
\text { red-edge }\end{array}$ & $\frac{N I R-R E}{N I R+R E}$ & Gitelson and Merzlyak (1994) ${ }^{16}$ \\
\hline PSRI & Plant Senescence Reflectance Index & $\frac{R-G}{R E}$ & Merzlyak et al. (1999) ${ }^{17}$ \\
\hline SRre & Simple Ratio red-edge & $\frac{N I R-G}{R E-G}$ & Sims and Gamon $(2000)^{18}$ \\
\hline MSRre & Modified Simple Ratio red-edge & $\frac{N I R / R E-1}{\sqrt{N I R / R E+1}}$ & Chen $(1996)^{19}$ \\
\hline
\end{tabular}

Next, digital values of the spectral indices were extracted in each plot to form the working database. The relationship between these values and field measured burn severity was analyzed by an analysis of variance (ANOVA) in which the values of these indices were grouped by burn severity class: high, moderate, low and not burned. The Fisher's Least Significant Difference (LSD) test determined which mean values of the samples were significantly different from the remaining average values.

\section{RESULTS}

The scatterplots among the 4 bands of the Parrot SEQUOIA sensor for the vegetation burn severity levels in the sampling plots were displayed in Figure 4. This matrix graph allowed us to obtain an initial view of the relationships between the bands for the different burn severity levels. The scatterplots between Green and Red bands are almost linear and show the high correlation between these bands and the low separability between burn severity levels. This linearity is also observed in the scatterplots between Red-edge and Near-infrared bands but with separability between the unburned zone and the rest. In contrast, the scatterplots between Green and Red versus Red-edge or Green and Red versus Near-infrared have a triangular shape, and show very little confusion between the different burn severity levels. 


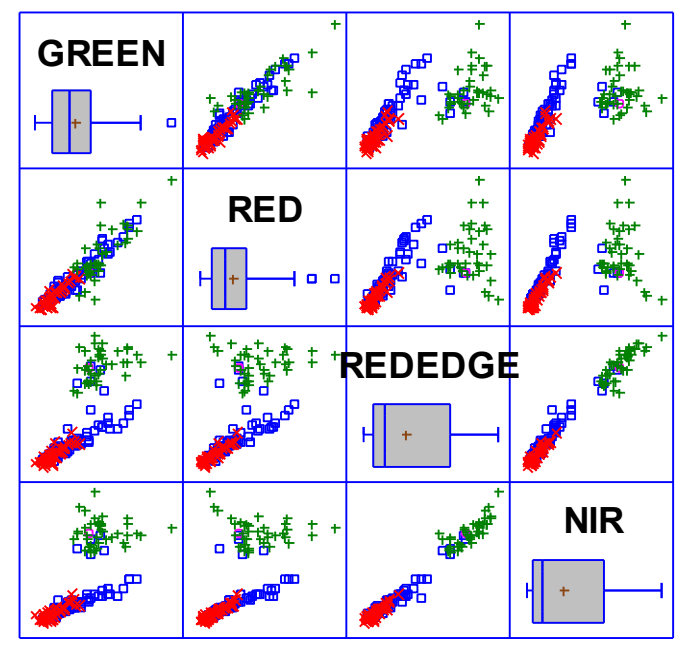

Figure 4. Scatterplots among the 4 bands of the SEQUOIA Parrot sensor for the vegetation burn severity levels: high burn severity

(blue), moderate blue severity (red), low burn severity (pink) and unburned (green)

Table 2 shows the results of the ANOVA analysis performed when vegetation burn severity was taken into account. Only DVI index made possible to distinguish significantly ( $\mathrm{p}$-value $<0.05$ ) the three levels of vegetation burn severity used (dark gray shading). NDVI and NDVIre were able to discern two of them, in some cases the moderate level was confused with the high level and in others with the low (light gray shading). Finally, MSRre, PSRI and SRre2 only allowed to discriminate the burned area from the unburned (without shading).

Table 2. LSD (Fisher's Least Significant Difference) test for spectral indexes and vegetation burn severity levels

\begin{tabular}{|c|c|c|c|c|c|c|}
\hline \multirow[t]{3}{*}{ Vegetation burn severity } & \multicolumn{6}{|c|}{ Spectral indexes } \\
\hline & \multicolumn{2}{|c|}{ NDVI } & \multicolumn{2}{|c|}{ DVI } & \multicolumn{2}{|c|}{ NDVIre } \\
\hline & $\mu$ & $\mathrm{HG}$ & $\mu$ & $\mathrm{HG}$ & $\mu$ & $\mathrm{HG}$ \\
\hline High & 0,03 & $\bar{a}$ & 0,00 & $\mathrm{a}$ & $-0,00$ & $\mathrm{a}$ \\
\hline Moderate & 0,10 & $\mathrm{~b}$ & 0,00 & $\mathrm{~b}$ & $-0,00$ & $a$ \\
\hline Low & 0,12 & $\mathrm{~b}$ & 0,02 & $\mathrm{c}$ & 0,01 & $\mathrm{~b}$ \\
\hline \multirow[t]{3}{*}{ Unburned } & 0,48 & $\mathrm{c}$ & 0.37 & $\mathrm{~d}$ & 0.08 & $\mathrm{c}$ \\
\hline & \multicolumn{2}{|c|}{ MSRre } & \multicolumn{2}{|c|}{ PSRI } & \multicolumn{2}{|c|}{ SRre } \\
\hline & $\mu$ & $\mathrm{HG}$ & $\mu$ & HG & $\mu$ & $\mathrm{HG}$ \\
\hline High & $-0,00$ & $\mathrm{a}$ & 0,03 & $\mathrm{a}$ & 1,21 & $\mathrm{a}$ \\
\hline Moderate & $-0,00$ & $\mathrm{a}$ & 0,06 & $\mathrm{a}$ & 1,23 & $\mathrm{a}$ \\
\hline Low & 0,00 & $\mathrm{a}$ & 0,09 & $\mathrm{a}$ & 1,32 & $\mathrm{a}$ \\
\hline Unburned & 0.08 & $\mathrm{~b}$ & 0,13 & $\mathrm{~b}$ & 3,11 & $\mathrm{~b}$ \\
\hline
\end{tabular}

$\mu$ : mean; HG: homogeneous groups, different letters in HG column indicate a group of means among which there are no significant differences $(\mathrm{p}$-valor $<0,05)$

The ANOVA results when soil burn severity was used were displayed in Table 3. Both NDVI and NDVIre indexes made possible to distinguish significantly (p-value $<0.05$ ) the two levels of soil burn severity used (gray shading). The rest of tested indexes (DVI, MSRre, PSRI, and SRre) only allowed to discriminate the burned area from the unburned (without shading).

Table 3. LSD (Fisher's Least Significant Difference) test for spectral indexes and soil burn severity levels

\begin{tabular}{|c|c|c|c|c|c|c|}
\hline \multirow[t]{3}{*}{ Soil burn severity } & \multicolumn{6}{|c|}{ Spectral indexes } \\
\hline & \multicolumn{2}{|c|}{ NDVI } & \multicolumn{2}{|c|}{ DVI } & \multicolumn{2}{|c|}{ NDVIre } \\
\hline & $u$ & $\mathrm{HG}$ & $u$ & $\mathrm{HG}$ & $\mu$ & $\mathrm{HG}$ \\
\hline High & 0,03 & $\mathrm{a}$ & 0,00 & $\mathrm{a}$ & $-0,00$ & $\mathrm{a}$ \\
\hline Moderate-low & 0,10 & $\mathrm{~b}$ & 0,00 & $\mathrm{~b}$ & 0,03 & $\mathrm{~b}$ \\
\hline \multirow[t]{3}{*}{ Unburned } & 0,48 & $\mathrm{c}$ & 0.37 & $\mathrm{~b}$ & 0.08 & $\mathrm{c}$ \\
\hline & \multicolumn{2}{|c|}{ MSRre } & \multicolumn{2}{|c|}{ PSRI } & \multicolumn{2}{|c|}{ SRre } \\
\hline & $\mu$ & HG & $\mu$ & $\mathrm{HG}$ & $\mu$ & $\mathrm{HG}$ \\
\hline High & $-0,00$ & $\mathrm{a}$ & 0,03 & $\mathrm{a}$ & 1,21 & $\mathrm{a}$ \\
\hline Moderate & $-0,00$ & $\mathrm{a}$ & 0,06 & $\mathrm{a}$ & 1,23 & $\mathrm{a}$ \\
\hline Unburned & 0.08 & $\mathrm{~b}$ & 0,13 & $\mathrm{~b}$ & 3,11 & $\mathrm{~b}$ \\
\hline
\end{tabular}

$\mu$ : mean; HG: homogeneous groups, different letters in HG column indicate a group of means among which there are no significant differences (p-valor $<0,05$ ) 


\section{DISCUSSION}

Our study confirmed the usefulness of UAV multispectral data for discriminate burned from unburned areas and vegetation and soil burn severity levels in two prescribed burnings. All the tested spectral indexes distinguished with statistical significance burned and unburned classes. Regarding vegetation burn severity, one index enabled to discriminate three burn severity level and two indexes discriminated two burn severity levels. Regarding soil burn severity, two spectral indexes discriminated the two considered levels. In this sense, our work agrees with previous research woks showing the validity of UAV multispectral data for analyze fire damage ${ }^{3,4,5}$. Fraser et al. $(2017)^{4}$ used UAV RGB data and showed that it was possible to identify burned area in Boreal forests and discriminate burn severity as well. Fernández-Guisuraga et al. (2018) ${ }^{3}$ compared the performance of UAV multispectral data to WorldView-2 data in Mediterranean Pine forests. They affirmed that the spatial information provided by the ultra-high spatial resolution UAV multispectral data was not redundant in comparison with high spatial resolution satellite imagery such as that provided byWorldView-2. Thus, the UAV multispectral data could improve the analysis and interpretation of fine-scale ground patterns.

With regards to the type of spectral index used to identify fire damage, our study showed that both conventional and rededge based spectral indexes have the same performance. In this sense, our results differ to some extent with results from previous research works. Fernández-Manso et al. $(2016)^{10}$ using Sentinel-2 data found that NDVI versions based on NIR and "red-edge" wavelengths provide a pseudo-R2 statistic greater than NDVI when related to vegetation burn severity measurements. Conversely, in our study both NDVI and NDVIre (its "red-edge" version) allowed to distinguish only two levels of severity. Similarly, Filipponi $(2018)^{11}$ proposed a new red-edge based spectral index for burned area mapping that showed a good performance of compared to NBR index and Copernicus EMS products. However, our work showed that all spectral indexes (both red-edge based and conventional) showed the same performance when discriminating burned areas. Our work agrees however with the study of Amos et al., $(2019)^{20}$ who observed that the performance of red-edge based spectral indexes was inferior than performance of conventional indexes for discriminating burn severity levels in Mediterranean wildfires. And with the work of Díaz-Delgado et al. (2003) ${ }^{21}$ that also found a positive correlation between the drop in NDVI index values and fire severity levels inside fire's perimeter in Northeast Spain. A possible cause of these differences among the performance of the different spectral indexes is the type of study area. Our study area is a zone where fires are recurrent, and vegetation is limited to scrubs. In addition, we analyzed prescribed burnings instead of a real wildfire.

Unfortunately, we did not find any study relating UAV multispectral data and soil burn severity. Our research work showed the suitability of this kind of data for identifying two soil burn severity levels in prescribed burnings.

\section{CONCLUSIONS}

Multispectral data from UAV is able to identify burned area in prescribed burnings carried out in Mediterranean scrubs. In addition, these data enable to discriminate three vegetation burn severity levels and two soil burn severity levels. Conventional and red-edge based spectral indexes showed a similar performance for discriminating burned area and burn severity. However, future research is needed to extend the findings of this preliminary work to other ecosystems and forest fire regimes.

\section{ACKNOWLEDGEMENT}

The work is part of the projects: FIRESEVES (AGL2017-86075-C2-1-R) funded by the Spanish Ministry of Economy and Competitiveness and the European Regional Development Fund, and SEFIRECYL (LE001P17), financed by the government of the autonomous community of Castilla y León. The authors would like to thank the collaboration in the study of the company Heligrafics. 


\section{REFERENCES}

[1] Fernandes, P.M., Davies, G.M., Ascoli, D., Fernandez, C., Moreira, F., Rigolot, E., Stoof, C.R., Vega, J.A. and Molina, D. "Prescribed burning in southern Europe: developing fire management in a dynamic landscape," Front. Ecol. Environ., 11, E4-E14 (2013)

[2] Prichard, S.J. Kennedy, M.C. Wright, C.S. Cronan, J.B and Ottmar, R.D. "Predicting forest floor and woody fuel consumption from prescribed burns in southern and western pine ecosystems of the United States," Forest Ecol. Manag., 405, 328-338 (2017)

[3] Fernández-Guisuraga, JM, Sanz-Ablanedo, E, Suárez-Seoane, S. and Calvo, L. "Using Unmanned Aerial Vehicles in Postfire Vegetation Survey Campaigns through Large and Heterogeneous Areas: Opportunities and Challenges," Sensors. 18 (2) (2018)

[4] Fraser, R.H., van der Sluijs, J. and Hall, R.J. "Calibrating Satellite-Based Indices of Burn Severity from UAVDerived Metrics of a Burned Boreal Forest in NWT, Canada," Remote Sens., 9, 279 (2017)

[5] McKenna, P., Erskine, P.D., Lechner, A.M. and Phinn, S. "Measuring fire severity using UAV imagery in semi-arid central Queensland, Australia," Int. J. Remote Sens., 38, 4244-4264 (2017)

[6] Shang, J., Liu, J., Ma, B., Zhao, T., Jiao, X., Geng, X., Huffman, T., Kovacs, J.M. and Walters, D. "Mapping spatial variability of crop growth conditions using RapidEye data in Northern Ontario, Canada," Remote Sens. Environ., $168,113-125(2015)$

[7] Schuster, C., Förster, M. and Kleinschmit, B. "Testing the red-edge channel for improving land-use classifications based on high-resolution multi-spectral satellite data," Int. J. Remote Sens., 33, 5583-5599 (2012)

[8] Adamczyk, J. and Osberger, A. "Red-edge vegetation indices for detecting and assessing disturbances in Norway spruce dominated mountain,” Int. J. Appl. Earth Obs., 37, 90-99 (2015)

[9] Chuvieco, E., Riaño, D., Danson, F.M. and Martín, P. "Use of radiative transfer model to simulate to postfire spectral response to burn severity," J. Geophys. Res, 111, G04S09 (2006)

[10] Fernández-Manso, A. Fernández-Manso, O. And Quintano, C. "SENTINEL-2A red-edge spectral indices suitability for discriminating burn severity," Int. J. Appl. Earth Obs., 50, 170-175 (2016)

[11] Filipponi, F. "BAIS2: Burned Area Index for Sentinel-2," Proceeding of the 2nd International Electronic Conference on Remote Sensing 2(7), 364 (2018)

[12] Key, C.H. and Benson, N.C. "Landscape assessment: Sampling and analysis methods: Firemon: Fire effects monitoring and inventory system," General Technical Report. USDA Forest Service, Rocky Mountain Research Station, Fort Collins CO., RMRS-GTR-164-CD. (2006)

[13] Segl, K., Guanter, L., Gascon, F., Kuester, T., Rogass, C., Mielke, C. "S2eteS: And end-to-end modelling tool for the simulation of Sentinel-2 image products," IEEE T. Geosci. Remote, 53, 5560-5571 (2015)

[14] Hill, M.J. "Vegetation index suites as indicators of vegetation state in grassland and savanna: An analysis with simulated SENTINEL-2 data for a North American transect," Remote Sens. Environ., 137, 94-111 (2013)

[15] Tucker, C.J. "Red and photographic infrared linear combinations for monitoring vegetation," Remote Sens. Environ, 8, 127-150 (1979)

[16] Gitelson, A., and Merzlyak M.N. "Spectral reflectance changes associated with autmn senescence of aesculus hippocastanum L. and Acer platanoides L. leaves: Spectral features and relation to chlorophyll estimation. J. Plant Physiol., 143, 286-292 (1994)

[17] Merzlyak, J.R., Gitelson, A.A., Chivkunova, O. B. and Rakitin, V.Y. "Non-destructive optical detection of pigment changes during leaf senescence and fruit ripening," Physiol. Plantarum, 106, 135-141 (1999)

[18] Sims, D. and Gamon, J. "Relationships Between Leaf Pigment Content and Spectral Reflectance Across a Wide Range of Species, Leaf Structures and Developmental Stages," Remote Sens. Environ, 81, 337-354 (2002)

[19] Chen, J. "Evaluation of Vegetation Indices and Modified Simple Ratio for Boreal Applications," Can. J. Remote Sens. 22, 229-242 (1996)

[20] Amos, C., Petropoulos G.P. and Ferentinos, K.P. "Determining the use of Sentinel-2A MSI for wildfire burning \& severity detection," Int. J. Remote Sens., 40:3, 905-930 (2019)

[21] Díaz-Delgado, R., Lloret, F. and Pons, X. "Influence of fire severity on plantregeneration through remote sensing imagery,” Int. J. Remote Sens. 24, 1751-1763 (2003) 